\title{
The Effect of Aspalathin on Levels of Sugar and Lipids in Streptozotocin-Induced Diabetic and Normal Rats
}

\author{
Mahmood Najafian, ${ }^{1,{ }^{*}}$ Bahareh Najafian, ${ }^{2}$ and Zahra Najafian ${ }^{3}$ \\ ${ }^{1}$ Endocrinology and Metabolism Research Institute, Tehran University of Medical Sciences, Tehran, Iran \\ ${ }^{2}$ Department of Biology, Shiraz Education District 4, Shiraz, Iran \\ ${ }^{3}$ School of Nursing, Medical University of Zabol, Zabol, Iran \\ "Corresponding author: Mahmood Najafian, Endocrinology and Metabolism Research Institute, Tehran University of Medical Sciences, Tehran, Iran. E-mail: \\ mn.najafian@yahoo.com
}

Received 2015 December 06; Revised 2016 February 10; Accepted 2016 October 28.

\begin{abstract}
Background: Flavonoids have been reported as mammalian alpha-amylase inhibitors, a property which could be useful in the management of postprandial hyperglycemia in diabetes and its related disorders.

Objectives: In the present study the inhibitory effect of aspalathin as a flavonoid on alpha amylase activity and levels of sugar and lipids in rats, has been investigated.

Methods: In this experimental study, type inhibition of aspalatin on amylase and in the part of in vivo, the effect of aspalathin orally doses 5,10, 20 and $40 \mathrm{mg} / \mathrm{kg}$ body weight on sugar and lipids levels was tested in a streptozotocin-induced model of diabetes and normal rats. The data were analyzed by one-sample Kolmogrov-Smirnov, Levene and ANOVA tests through SPSS version 22.

Results: The results showed that aspalathin is a competitive inhibitor for alpha amylase with $\mathrm{Ki}=37.0 \mu \mathrm{M}$. In both diabetic and normal groups in all doses nearly dose dependent manner reduced blood glucose levels and beneficial effect on dyslipidemia were observed in diabetic rats, as well as reduction of disturbing consequences of diabetes such as high urine volume and water intake. Aspalathin was observed to have a weight loss-inductive effect, alongside with a reduction in food intake.

Conclusions: It seems that, this compound could be proposed as an antihyperglycemic and antihyperlipidemic agent in diabetes and potential therapeutic in obesity.
\end{abstract}

Keywords: Aspalathin, Alpha amylase, Diabetes, Hyperglycemia, Hyperlipidemia

\section{Background}

Overweight, obesity and diabetes are the most common disorders in developed societies. In most diets, carbohydrates are the greatest source of calories. Inhibition of carbohydrate digestion or absorption can decrease calorie intake to promote weight loss and combat obesity. It is also a mechanism for reducing hyperglycemia in diabetic subjects [1]. Being obese increases the risk of arthritis, dyslipidemia, hypertension, diabetes, and coronary artery disease [2]. The most important methods for treatment of diabetes are inhibition of digestion and absorption of carbohydrates in small intestine. That is occurring in two manners. The first is inhibition digestion of carbohydrates with inhibition of alpha amylase, the enzyme that decompose of carbohydrates and the second is inhibition of absorption via sodium/glucose cotransporters (SGLT1 and SGLT2), the sugar transporter systems [3]. Alpha-amylase catalyzes the hydrolysis of $\alpha$-(1,4)-D-glycosidic linkages of starch and other glucose polymers. Inhibitors of this enzyme can be used in the treatment of diabetes [3]. Different types of oral antidiabetic agents such as biguanides and sulphonylurea are available along with insulin for the treatment of diabetes mellitus, but have side effects associated with their uses [4]. A large number of studies are in progress to identify natural substances that are effective in reducing the severity of diabetes. Ayurveda is a science that uses herbal medicines. From ancient times, some of these herbal preparations have been used in the treatment of diabetes. Even the world health organization (WHO) approves the use of plant drugs for different diseases, including diabetes mellitus [5, 6]. Polyphenolic compounds such as flavonoids are widely distributed in plants and fruits and are present in normal diets. These compounds have been shown to possess beneficial effects in diabetes, cardiovascular diseases, atherosclerosis, allergy, inflammation, cancer, asthma and osteoporosis [7-10]. Flavonoids based on differences in molecular backbone structure may be divided into eight different classes (flavonols, flavones, flavanones, catechins, anthocyanidins, isoflavones, dihydroflavonols, and chalcones) [1]. Flavonoid- rich fractions 
of plants have also been reported to be effective as antihyperglycemic and antihyperlipidemic agents in animal models of diabetes [11]. Plants derived polyphenols such as quercetagetin, fisetin, and quercetin, which belong to the flavonoid family, have been shown to be effective inhibitors of mammalian alpha-amylase with IC50s in the order of $\mu \mathrm{M}$ [1]. Aspalathin (Asp) is the major active dihydrochalcones found in green rooibos, which have been reported many interesting biological properties [12]. These include its antiinflammatory, antioxidant, antidiabetic, antihyperuricemic $[13,14]$. Also rooibos tea is used for hyperactive gastrointestinal, respiratory and cardiovascular disorders [15].

\section{Objectives}

Since aspalathin could be viewed as a flavonoid of polyphenolic compounds, in this investigation we researched the inhibitory effect of aspalathin on alpha amylase activity and the effect of aspalathin orally on levels of sugar and lipids in streptozotocin-induced diabetic and normal rats.

\section{Methods}

\subsection{Chemicals}

In this experimental study, porcine pancreatic alpha amylase (PPA), aspalathin, dialysis membrane, 3, 5dinitrosalisylate reagent (DNS) and sodium potassium tartrate were from Sigma Chemicals Company (St Louis, MO, USA). Streptozotocin was from Pharmacia \& Upjohn (Kalamazoo, MI, USA). Dimethyl sulfoxide, soluble starch, maltose and other chemicals were obtained from Merck Chemicals Company (Darmstadt, Germany).

\subsection{Determination Activity of Amylase}

Bernfeld method was used for the enzyme assay [13]. Aspalathin was dissolved in dimethyl sulfoxide (DMSO) and used as inhibitor of alpha amylase activity. Starch was dissolved in a phosphate buffer $\mathrm{pH} 7 \mathrm{w} / \mathrm{v}: 0.5 \%, 1.0 \%$, $1.5 \%, 2.0 \%$ and $2.5 \%$ ) and used as substrate of alpha amylase. The enzyme was previously incubated for $30 \mathrm{~min}$ utes in the presence of various concentrations $(0,50,100$ and $150 \mu \mathrm{M}$ ) of aspalathin (as sample test) and DMSO (as control). Then added starch solution and incubated in room tempreture for 3 minutes. After this time, the reaction was stopped by the addition of 3, 5-Dinitrosalicylic acid (DNS) reagent. Samples were then placed in a boiling water bath for 5 minutes and subsequently cooled down to room temperature, then added $5 \mathrm{ml}$ distilled water and was mixed. Absorbance was measured at $540 \mathrm{~nm}$ against a blank prepared using the identical method, except the enzyme solution was added to the mixture after the addition of the DNS solution. The optical density (OD) values were then converted to micromole of maltose equivalent using a standard curve obtained from the known concentration of maltose prepared with the same buffer solutions $(\mathrm{Y}=$ $0.0001 X+0.0025)$. A unit of enzyme activity was defined as the amount of enzyme that released one micromole of maltose per minute under the assay conditions specified. Remaining activity was calculated as a percentage by comparison with the control sample activity, the activity of enzyme in presence of DMSO. All experiments were done at least three times and average values reported [16,17].

\subsection{Dialysis Enzyme-Inhibitor}

Reversibility of inhibition was checked with the technique of dialysis tube. Enzyme-aspalathin was dialised in dialysis tube in $0^{\circ} \mathrm{C}$ for 24 hours. Enzyme activity in the presence of aspalathin was measured and comparing this value with the one obtained after extensive dialysis of the enzyme-aspalathin solution, show that nearly all aspalathin go out of dialysis tube. This means that the attachment of aspalathin to enzyme is reversible.

\subsection{Animals}

All rats were male wistar, weighting $190 \pm 10 \mathrm{~g}$ and 2.5 months age. They were kept in cages in groups of six, inside a room at temperature of $22-24^{\circ} \mathrm{C}$. During daylight hours (8:00 to 20:00) room lights were turned on. They were fed with standard rodent diet. Rats were given ad libitum access to food and water. For a week prior to the experiment, diabetic state was induced by a single intraperitoneal injection of streptozotocin (STZ) (70 mg/kg body weight, dissolved in a citrate buffer $0.1 \mathrm{M}, \mathrm{pH} 4.5)$. After a week, blood glucose levels were measured in $2 \mu \mathrm{L}$ blood samples extracted from the tail of the animal with a glucometer (One Touch Profile, Life Scan) [18, 19]. Different doses of aspalathin and grape seed oil (as solvent of aspalathin) were administrated orally for 21 days through a gastric cannula in a single dose $(0.5 \mathrm{~mL})$ at $8: 30$ a.m. Rats were divided into two major groups, "normal rats" $(\mathrm{N})$ and "diabetic rats" (D), and each was subsequently divided into five subgroups(each group include 6 rats), as defined below: (I) Normal control group (NO): rats in this group received grape seed oil (O).(II) Normal experimental groups: rats in these groups received aspalathin at 5, 10, 20 and $40 \mathrm{mg} / \mathrm{kg}$ body weight (groups were named, NA5, NA10, NA20 and NA40 respectively). (III) Diabetic control group (DO): rats in this group received grape seed oil (O). (IV) Diabetic experimental groups: rats in these groups received aspalathin at 5, 10, 20 and $40 \mathrm{mg} / \mathrm{kg}$ body weight (groups were named, DA5, DA10, DA20 and DA40 respectively). 
The doses were chosen based on our in vitro experiences with aspalathin, as well as considering our previous study on trans-chalcone whose in vitro and in vivo effects were both studied as a potential hypoglycemic agent [18]. The ethical aspect of the experimental protocol was approved by the ethical committee of the Science and Research Branch of Islamic Azad University (Tehran, Iran).

\subsection{Measured Parameters}

Food intake, water intake and urine volume were measured every morning at 9:00 a.m. with metabolic cage. Blood glucose levels were measured in $2 \mu \mathrm{L}$ blood samples extracted from the tail of the animal every week in the mornings at 9:00 a.m. with a glucometer (One Touch Profile, Life Scan). At the end of experiment period, the body weight of all animals was measured and they were sacrificed under light ether anesthesia. The abdomen was cut open, and blood collected from heart. Blood samples were placed on ice and centrifuged within 15 minutes after collection at $3000 \mathrm{~g}$ for five minutes. Serum was stored at $20^{\circ} \mathrm{C}$ for less than 1 week before subsequent analyses. Standard biochemical methods were used to measure cholesterol, triglycerides, high density lipoproteins (HDL), lowdensity lipoproteins (LDL) concentrations. Estimates of very low density lipoprotein (VLDL) were calculated from the formula (VLDL-C = triacylglycerol/5) [18].

\subsection{Statistical Analysis}

The data were analyzed with SPSS version 22. Standard deviation was calculated in all cases and results expressed as mean \pm SD. The data were analyzed by onesample Kolmogrov-Smirnov test and then by the Levene's test. One way analysis of variance (ANOVA) followed by Tukey's post hoc test for multiple comparisons were used to compare difference between experimental groups. The criterion for statistical significant was $\mathrm{P}<0.05$.

\section{Results}

With the technique of dialysis tube was showed that the attachment of aspalathin to enzyme is reversible. Aspalathin inhibited alpha amylase activity with an half maximal inhibitory concentration (IC50) value IC $_{50}=91.7 \mu \mathrm{M}$. Graphical double reciprocal plots, Lineweaver-Burk plots showed that Aspalathin is a competitive inhibitor for alpha amylase (Figure 1). According to the equation of the line of zero concentration of inhibitor, $(y=0.0005 x+0.0005), \mathrm{Km}$ $=1.0 \%$ Starch and $\mathrm{Vm}=2000 \mu$ Mole $/ \mathrm{min}$.

Dixon plot was subsequently drawn for aspalathin and a Ki of $37.0 \mu \mathrm{M}$ was obtained for this compound (Figure 2).

\subsection{Effect of Aspalathin on Blood Glucose Levels}

Administration of STZ resulted in high level of blood glucose $(398.8 \pm 19.1 \mathrm{mg} / \mathrm{dL})$ after 1 week in the treated group in contrast with the normal control group in which blood glucose levels were in the range of $108.5 \pm 5.7 \mathrm{mg} / \mathrm{dL}$. In the normal control group (NO) and in the diabetic control group (DO) blood glucose remained nearly constant throughout the experimental period at about 104.3-108.5 and 394.2-402.2 mg/dL respectively. A decrease in glycemia was occurred rapidly in first week after aspalathin administration in all the doses used. This decline was occurred mildly until the end of the experimental period. The effect appears to be dose dependent, but there was no significant difference between the two doses of 20 and $40 \mathrm{mg} / \mathrm{kg}$ (Figures 3 and 4).

\subsection{Effect of Aspalathin on Blood Lipid Levels}

Blood lipid levels of diabetic rats were found to be elevated (As shown in Table 1). In the diabetic control group, in contrast to the normal control group (As shown in Table 2 ), a marked elevation was observed in the concentration of serum cholesterol (46\%), TG (55\%), VLDL (55\%), and LDL (85\%), while the concentration of HDL was reduced by $26 \%$. This lipid profile was remarkably improved after administration of aspalathin. It is observed that the two doses 20 and $40 \mathrm{mg} / \mathrm{kg}$ body weight had nearly similar effect on lipid profile. Blood lipid levels of normal rats were also modified upon its administration (Table 2). It could be observed that in the experimental groups, the two doses 20 and $40 \mathrm{mg} / \mathrm{kg}$ body weight had nearly similar reducing effect on the concentrations of cholesterol, TG, VLDL, and LDL, while no significant effect was found on HDL.

\subsection{Effect of Aspalathin on Food Intake and Body Weight}

Higher food consumption of diabetic groups compared with non-diabetics would be a characteristic of the disease state. As shown in figure 5 , food intake was significantly increased in the diabetic control group (DO) compared with the normal control group (NO) (47.2\%) (34.6 \pm $4.4 \mathrm{~g}$ v $23.5 \pm 2.9 \mathrm{~g}, \mathrm{P}<0.01)$. As a known consequence of type 1 diabetes, the body weight in the diabetic control group was significantly reduced in comparison with the non-diabetic control group (Figure 6) (29.2\%) (198.7 \pm 21.2 v 239.4 $\pm 25.7, \mathrm{P}<0.01)$. Aspalathin intake results in a decrease of food consumption, as well as a marked lowering in the weight of the rats which were receiving the treatment (Figures 5 and 6). The effect is similarly observed in both diabetic and normal rats, but is slightly more pronounced in the normal rats. 
Figure 1. Linewear-Burk Plot Used to Determine the Type Inhibition of Aspalathin Toward PPA

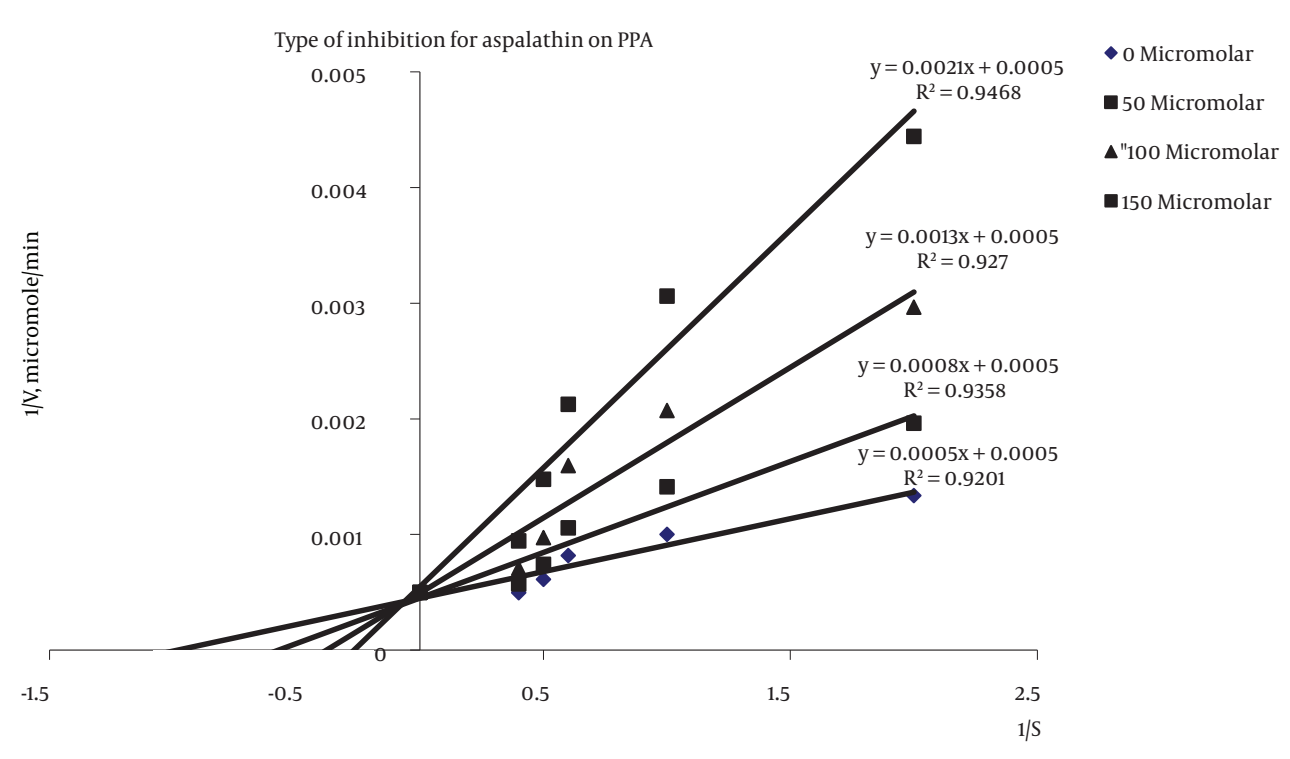

Reverse values of activity $(1 / \mathrm{V})$ and substrate concentration $(1 / \mathrm{S}) \mathrm{w} / \mathrm{v}$ : $0.5 \%, 1.0 \%, 1.5,2.0 \%, 2.5 \%$ are plotted in absence of aspalathin $((\bullet$, and presence of three different concentrations of aspalathin: $50 \mu \mathrm{M}(\mathbf{\square}), 100 \mu \mathrm{M}(\mathbf{\Lambda}), 150 \mu \mathrm{M}(\mathbf{\square})$. According to the equation of the line of zero concentration of inhibitor, $(\mathrm{y}=0.0005 \mathrm{x}+0.0005), \mathrm{Km}=1.0 \% \mathrm{Starch}$ and $\mathrm{Vm}=2000 \mu \mathrm{Mole} / \mathrm{min}$.

Figure 2. Dixon Plot Used to Find the Ki of Aspalathin

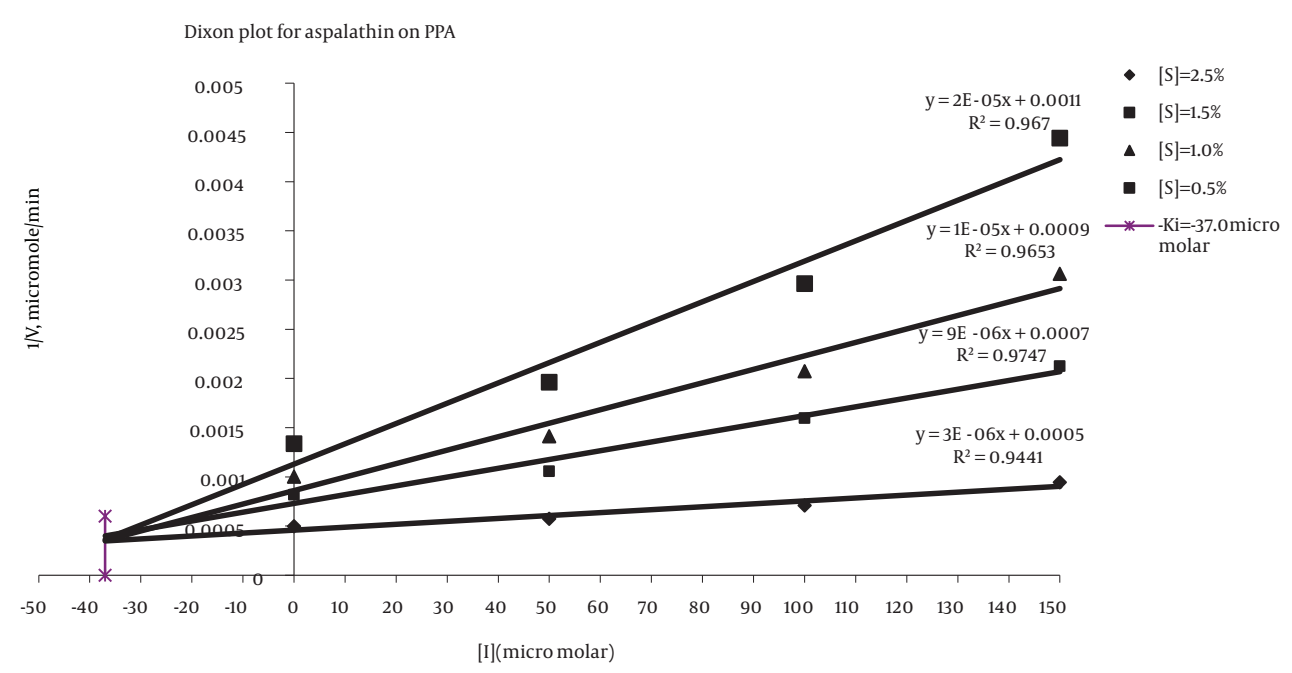

Reverse values of activities $(1 / \mathrm{V})$ are plotted against $0,50,100$, and $150 \mu \mathrm{M}$ of aspalathin[I], with the use of four different concentrations of the substrate expressed as w/v: $2.5 \%$ $(\bullet), 1.5 \%(\square), 1.0 \%(\boldsymbol{\Delta}), 0.5 \%(\mathbf{\square})$.Ki of this compound was $37.0 \mu \mathrm{M}$.

\subsection{Effect of Aspalathin on Water Intake and Urine Volume}

As a logical characteristic of the diabetic state, water intake was observed which has a significantly increase in the diabetic control group (DO) compared with normal control group (NO) $(114.5 \pm 12.7 \mathrm{~mL}$ v. $37.6 \pm 4.1 \mathrm{~mL}, \mathrm{P}<0.001)$ (Figure 7). As a well-known consequence of becoming di- abetic, in diabetic control group (DO), urine volume was significantly increased in comparison with normal control group (NO) (97.4 $\pm 10.6 \mathrm{~mL}$ v. $19.3 \pm 2.2 \mathrm{~mL}, \mathrm{P}<0.001$ )(Figure 7). In diabetic groups' administration of aspalathin reduced water intake and urine volume nearly in a dosedependent manner, but in the normal rats, aspalathin did 
Table 1. Effect of Aspalathin Treatment on Serum Lipids of Diabetic Rats ${ }^{\mathrm{a}}$

\begin{tabular}{|c|c|c|c|c|c|}
\hline Serum Level, mg/dL & DO & DA5 & DA10 & DA20 & DA40 \\
\hline Cholesterol & $131.1 \pm 14.2$ & $111.6 \pm 13.3^{b}$ & $101.5 \pm 11.8^{b}$ & $98.1 \pm 12.6^{\mathrm{b}}$ & $95.4 \pm 10.8^{b, c}$ \\
\hline Triglycerides & $125.8 \pm 15.3$ & $112.7 \pm 13.4$ & $98.9 \pm 11.8^{\mathrm{b}}$ & $89.3 \pm 10.2^{\mathrm{b}, \mathrm{c}}$ & $87.8 \pm 10.9^{b, c}$ \\
\hline VLDL-C & $25.2 \pm 3.1$ & $22.5 \pm 2.7$ & $19.8 \pm 2.4^{\mathrm{b}}$ & $17.86 \pm 2.1^{\mathrm{b}, \mathrm{c}}$ & $17.6 \pm 2.2^{\mathrm{b}, \mathrm{c}}$ \\
\hline LDL-C & $60.2 \pm 7.8$ & $49.8 \pm 6.1^{b}$ & $38.6 \pm 5.3^{b, c}$ & $36.4 \pm 5.4^{\mathrm{b}, \mathrm{c}}$ & $34.5 \pm 5.2^{b, c}$ \\
\hline HDL-C & $33.1 \pm 3.3$ & $35.8 \pm 3.8^{\mathrm{b}}$ & $40.3 \pm 4.9^{\mathrm{b}}$ & $42.0 \pm 5.2^{\mathrm{b}, \mathrm{c}}$ & $43.3 \pm 4.8^{\mathrm{b}, \mathrm{c}}$ \\
\hline
\end{tabular}

${ }^{a}$ Data are expressed as mean \pm SD for six rats.

${ }^{\mathrm{b}}$ Significantly different from diabetic control group (DO).

${ }^{\mathrm{c}}$ Significantly different from DA5 $(\mathrm{P}<0.05)$.

Table 2. Effect of Aspalathin Treatment on Serum Lipids of Normal Rats ${ }^{\mathrm{a}}$

\begin{tabular}{|c|c|c|c|c|c|}
\hline Serum Level, mg/dL & No & NA5 & NA10 & NA20 & NA40 \\
\hline Cholesterol & $89.7 \pm 9.8$ & $86.4 \pm 10.1$ & $80.2 \pm 8.9$ & $78.5 \pm 7.3^{\mathrm{b}}$ & $76.8 \pm 8.7^{\mathrm{b}}$ \\
\hline Triglycerides & $80.9 \pm 9.1$ & $73.3 \pm 7.6$ & $69.8 \pm 7.9^{\mathrm{b}}$ & $66.4 \pm 7.4^{\mathrm{b}}$ & $65.7 \pm 7.1^{\mathrm{b}}$ \\
\hline VLDL-C & $16.2 \pm 1.8$ & $14.6 \pm 1.5$ & $13.9 \pm 1.6^{\mathrm{b}}$ & $13.3 \pm 1.5^{\mathrm{b}}$ & $13.1 \pm 1.4^{\mathrm{b}}$ \\
\hline LDL-C & $32.4 \pm 4.4$ & $30.1 \pm 4.1$ & $28.5 \pm 3.4$ & $27.3 \pm 3.1^{\mathrm{b}}$ & $26.4 \pm 2.9^{b}$ \\
\hline HDL-C & $44.7 \pm 5.8$ & $46.4 \pm 5.3$ & $47.3 \pm 6.2$ & $44.5 \pm 5.4$ & $43.9 \pm 5.9$ \\
\hline
\end{tabular}

${ }^{\text {a }}$ Data are expressed as mean \pm SD for six rats.

${ }^{\mathrm{b}}$ Significantly different from diabetic control group (NO) $(\mathrm{P}<0.05)$.

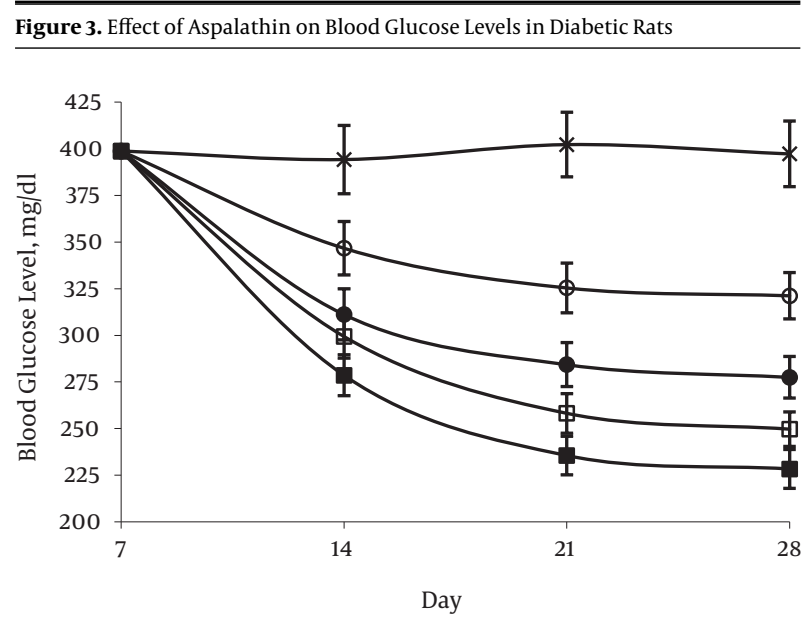

Rats were given grape seed oil $(\times)$ or aspalathin dissolved in oil of doses $5(0), 10(\bullet)$ $20(\square)$, and $40(\square)$ mg per kg body weight for 21days. Values are means \pm S.D.

not have any significant effect on these parameters.

\section{Discussion}

The result of this study showed that aspalathin is a competitive inhibitor of alpha amylase and reduced level
Figure 4. Effect of Aspalathin on Blood Glucose Levels in Normal Rats

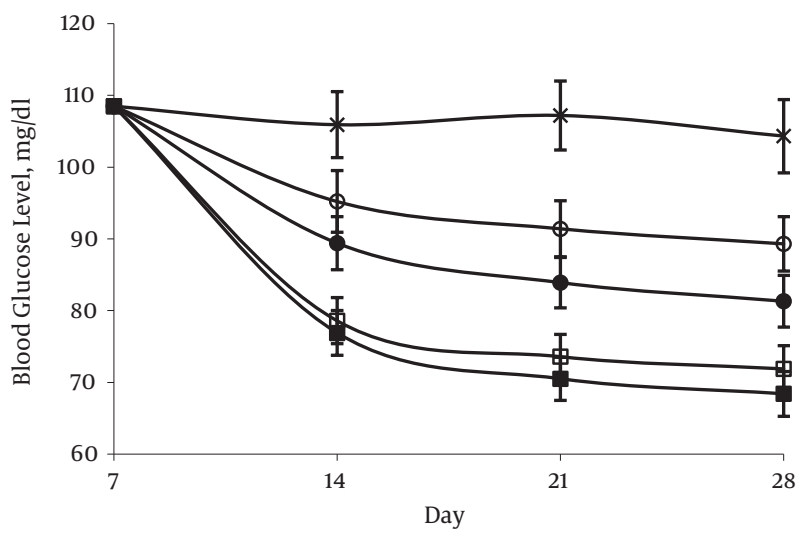

Rats were given grape seed oil $(X)$ or aspalathin dissolved in oil of doses $5(0), 10(\bullet)$ $20(\square)$, and $40(\square) \mathrm{mg}$ per kg body weight for 21days. Values are means \pm S.D.

of blood glucose in diabetic and normal rats. Furthermore this compound remarkably improved lipid profile specially in diabetic rats and also weight loss in all cases.

Diabetes mellitus is one of the most widespread diseases of world. According to the international diabetes federation (IDF), diabetes is one of the leading causes of mortality and morbidity in the modern world and reported 
Figure 5. Effect of Aspalathin Treatment on Food Intake in Diabetic and Normal Rats

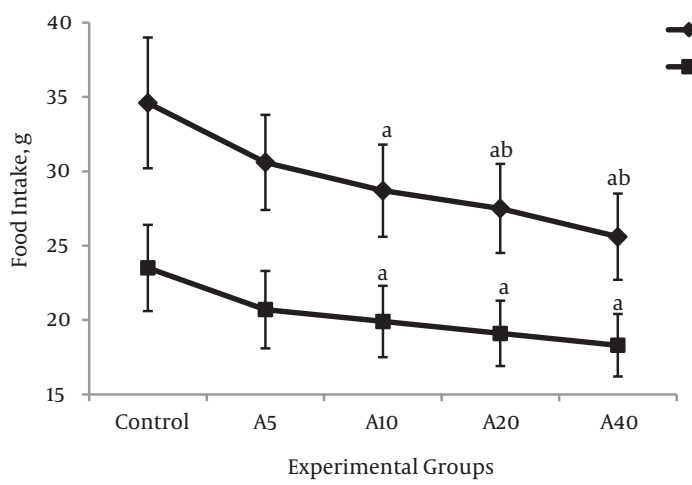

In each case (a) is significantly different from control groups and (b) is significantly different from Dose $5 \mathrm{mg} / \mathrm{kg}$-B.w.

Figure 6. Effect of Aspalathin Treatment on Body Weight in Diabetic and Normal Rats

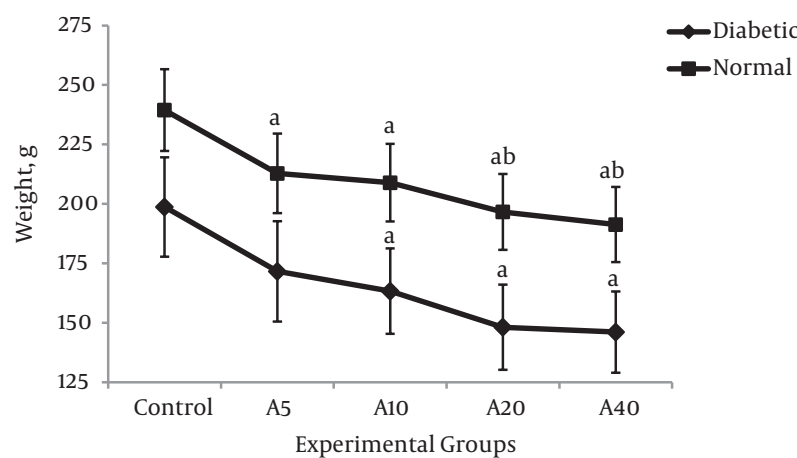

In each case (a) is significantly different from control groups and (b) is significantly different from Dose $5 \mathrm{mg} / \mathrm{kg}$-B.w.

to be among top causes of death in the recent years [1, 2]. Furthermore, as a chronic disease, diabetes is accompanied with serious kinds of complications such as vasculopathy, nephropathy, neuropathy and retinopathy [2022 ]. Diabetes is one of the most common endocrine disorders and is characterized by hyperglycemia, hypercholesterolemia, and hypertriglyceridemia [23]. Dyslipidemia is observed as a consequence of both type 1 and type 2 diabetes, and could contribute to an increased incidence of cardiovascular diseases if untreated. Atherosclerosis is also a major cause of cardiovascular disease caused by high cholesterol [7]. One of the most important methods for treatment of diabetes is inhibition of digestion of carbohydrates in small intestine. That is occurring inhibition digestion of carbohydrates with inhibition of the enzymes that decompose of carbohydrates such as alpha amylase and alpha glucosidase [3]. Classical inhibitors of mam- malian $\alpha$-amylase include protein and carbohydrate like structures, the latter mainly based on acarbose [24]. In recent years, small molecules have also been studied in this regard, and among these flavonoids have been reported to exhibit such activity similar to our previous experience on trans-chalcone and curcomin $[3,11,17,18]$. The aim of this research was to study the inhibitory effect of aspalathin, a chalcone derivative on alpha amylase activity and effect of this compound on levels of sugar and lipids in diabetic and normal rats. Aspalathin and nothofagin, the major dihydrochalcones in rooibos (Aspalathus linearis), are valuable bioactive compounds [25].

There are two types of rooibos tea: unfermented as green rooibos and fermented with oxidation of the constituent polyphenols, so the final product is often referred to as red tea or red bush tea. The most important characteristics of rooibos are its antioxidant, antimutagenic and antitumoral properties [26]. In this study Lineweaver-Burk plots showed that aspalathin is a competitive inhibitor of alpha amylase (Figure 1). With drawing Dixon plot it was determined that Ki of aspalathin on alpha amylase is 37.0 $\mu \mathrm{M}$ (Figure 2). The result of this study, the same as other our previous study on trans-chalcone $(\mathrm{Ki}=48 \mu \mathrm{M})$ and curcumin $(20.17 \mu \mathrm{M})$ showed that these compound are nearly highly potent inhibitor for alpha amylase activity [3, 11, 17, 18]. As mentioned before, new diabetic therapies seek ways to affect multiple targets at the same time with consideration of fewer side effects [27-30]. Our results indicate such a trend because administration of aspalathin in both diabetic and non-diabetic rats led to remarkable decrease in the level of blood glucose concentration and also inhibited the activity of alpha-amylase. Furthermore aspalathin is a chalcone derivative and seen that chalcone derivatives were found to act in a similar manner as insulin [31]. Besides, administration of aspalathin at different doses resulted in the correction of lipid profile. The general results of this study are the same as our previos study, the effect of flavonoids such as chalcone and curcumin on levels of sugar and lipids $[3,11,17,18]$. As shown in Figures 3 and 4 , a decrease in glycemia was occurred after aspalathin administration in all the doses used in diabetic and normal rats. The effect appears to be nearly dose dependent. This decrease in blood glucose levels may be occurred with inbibition of alpha amylase activity by aspalathin. A study showed that hypoglycemic effect of aspalathin is related to increased GLUT4 translocation to plasma membrane via AMP-activated protein kinase activation. In addition, aspalathin reduces the gene expression of hepatic enzymes related to gluconeogenesis and lipogenesis [32]. Furthermore chalcone derivatives have insulin mimetic properties [2]. Dyslipidemia is observed as a consequence of both type 1 and type 2 diabetes, and could contribute to an in- 


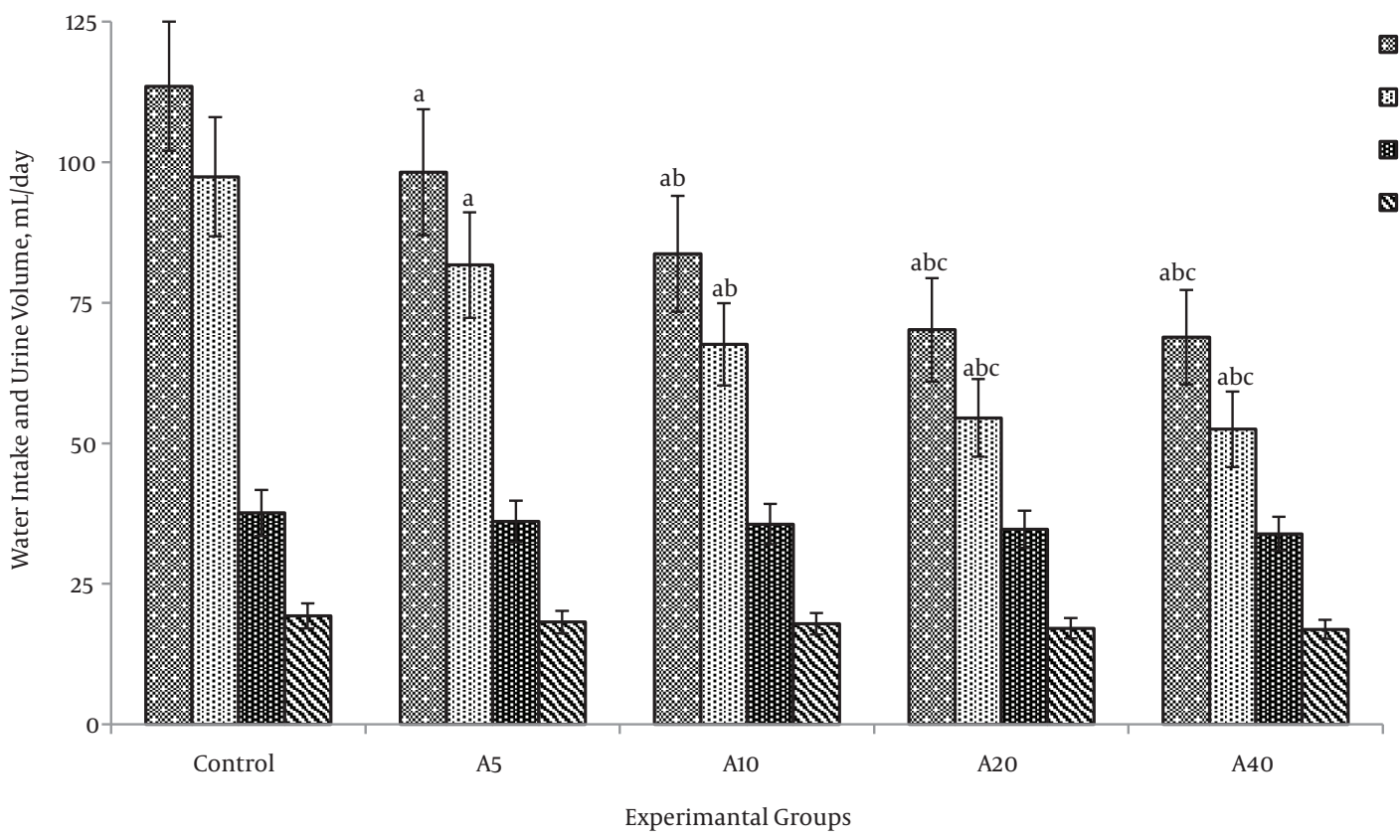

In each part (set columns, control and doses 5,10,20 and 40mg/kg-B.W) the first columns are water intake in diabetic rats, the second columns are urine volume in diabetic rats, the third columns are water intake in normal rats, the fourth columns are urine volume in normal rats. a: significantly different from DO (P < 0.05 ), b: significantly different from DA5 $(\mathrm{P}<0.05)$, C: significantly different from $\mathrm{DA1O}(\mathrm{P}<0.05)$.

creased incidence of cardiovascular diseases if untreated $[33,34]$. As shown in Table 1, blood lipid levels of diabetic rats were found to be elevated. In comparison with control group in table 2, a marked elevation was observed in the concentration of serum cholesterol, TG, VLDL, and LDL, while the concentration of HDL was reduced. This lipid profile was remarkably improved after administration of aspalathin. This study, the same as other our previous study on trans-chalcone, curcumin and phloridzin showed that these compounds can be considered as lipid lowering agentes $[7,11,18]$. A number of studies have shown that flavonoids improve lipid metabolism through various mechanisms.

Flavonoids by increasing excretion bile acid via increasing the amount mRNA of cholesterol $7 \alpha$-hydroxylase, and decreasing the level mRNA of HMG-CoA reductase, reduce the level of cholesterol and LDL [35-38].

Aspalathin reduce the level of triglycerides and VLDL in diabetic and normal rats. This maybe occured based on this actuality that chalcone derivatives cause increase the activity of fatty acid $\beta$-oxidation, hepatic lipase and lipoprotein lipase but decrease fatty acid syntheses activity [39-42].

Chalcone derivatives as antiatherosclerosis agent, cause increase the level of HDL via increasing the serum level of apolipoprotein A and the level of plasma lecithin cholesterol acyltransferase (LCAT) activity [41, 43]. In this case, this result is similar as other our previous study on trans-chalcone, curcumin and phloridzin.

As shown in Figures 5 and 6, with administration of aspalathin, weight loss and decrease of food intake were also observed in diabetic and normal rats. It may be due to aspalathin as a polyphenolic compound which could cause the reduction of calorie intake by inhibition of alpha amylase activity and decrease of carbohydrates digestion $[7,11$, 18]. It seems that aspalathin is an effective agent for the treatment and even the prevention of obesity.

As a well-known consequence of becoming diabetic, water intake and urine volume were observed to significantly increase in the diabetic rats (Figure 7). Aspalathin administration decreased the amount of water intake and urine volume by the diabetic groups nearly in a dosedependent manner. It is in accordance with its effect on blood glucose, and interesting in terms of the therapeutically benefits that it could have on these discomforting consequences of diabetes in patients. Aspalathin had no significantly effect on the water intake and urine volume in the normal groups.

In conclusion, aspalathin with $\alpha$-amylase inhibitory property, significant reduction in blood glucose, improve 
lipid profile and also weight loss, can considered as an effective compound in the treatment of diabetes.

In addition, this compound can be used as a basic structure to design drugs for inhibition of alpha amylase in the treatment of diabetes and obesity.

\section{Acknowledgments}

The authors are grateful to endocrinology and metabolism research institute, Tehran University of Medical Sciences and Razy laboratory center of university of science and research of Tehran.

\section{Footnotes}

Authors' Contribution: All authors had equal role in design, work, statistical analysis, and manuscript writing.

Funding/Support: Endocrinology and metabolism research institute, Tehran University of Medical Sciences.

\section{References}

1. Najafian M. A review of $\alpha$-amylase inhibitors on weight loss and glycemic control in pathological state such as obesity and diabete. Comp Clin Pathol. 2014;25(6):1-12. doi:10.1007/s00580-014-1967-x.

2. Rosak C, Mertes G. Effects of acarbose on proinsulin and insulin secretion and their potential significance for the intermediary metabolism and cardiovascular system. Curr Diabetes Rev. 2009;5(3):157-64. [PubMed:19689250].

3. Najafian M. Curcumin as Inhibitor of Alpha Amylase to Control of Diabetes. Zahedan J Res Med Sci. 2014:29-34.

4. Til A, Nirmal S, Pattan S, Tambe V, Tare M. Antidiabetic effect of polyherbal combinations in STZ induced diabetes involve inhibition of $\alpha$-amylase and $\alpha$-glucosidase with amelioration of lipid profile. Phytopharmacol. 2012;2(1):46-57.

5. Saxena A, Vikram NK. Role of selected Indian plants in management of type 2 diabetes: a review. J Altern Complement Med. 2004;10(2):36978. doi: 10.1089/107555304323062365. [PubMed: 15165418].

6. Najafian M, Ebrahim-Habibi A, Yaghmaei P, Parivar K, Larijani B. Citral as a potential antihyperlipidemic medicine in diabetes: a study on streptozotocin-induced diabetic rats. Iran J Diabetes and Lipid Disord. 2011;10:1-8.

7. Najafian M, Jahromi MZ, Nowroznejhad MJ, Khajeaian P, Kargar MM. Phloridzin reduces blood glucose levels and improves lipids metabolism in streptozotocin-induced diabetic rats. Mol Biol Rep. 2011;1(1):1-8

8. Russo GL. Ins and outs of dietary phytochemicals in cancer chemoprevention. Biochem Pharmacol. 2007;74(4):533-44. doi: 10.1016/j.bcp.2007.02.014. [PubMed: 17382300].

9. Woods RK, Walters EH, Raven JM, Wolfe R, Ireland PD, Thien FC, et al. Food and nutrient intakes and asthma risk in young adults. Am J Clin Nutr. 2003;78(3):414-21. [PubMed: 12936923].

10. Linseisen J, Rohrmann S, Miller AB, Bueno-de-Mesquita HB, Buchner FL, Vineis $P$, et al. Fruit and vegetable consumption and lung cancer risk: updated information from the European Prospective Investigation into Cancer and Nutrition (EPIC). Int J Cancer. 2007;121(5):1103-14. doi:10.1002/ijc.22807. [PubMed: 17487840].

11. Najafian M. Effect of Curcumin on Metabolism of Lipids in Streptozotocin Induced Diabetic and Normal Rats. Biomed Pharm J. 2014;7(1):383-91.
12. Ku SK, Kwak S, Kim Y, Bae JS. Aspalathin and Nothofagin from Rooibos (Aspalathus linearis) inhibits high glucose-induced inflammation in vitro and in vivo. Inflammation. 2015;38(1):445-55. doi:10.1007/s10753 014-0049-1. [PubMed: 25338943].

13. Kawano A, Nakamura H, Hata S, Minakawa M, Miura Y, Yagasaki K. Hypoglycemic effect of aspalathin, a rooibos tea component from Aspalathus linearis, in type 2 diabetic model $\mathrm{db} / \mathrm{db}$ mice. Phytomedicine. 2009;16(5):437-43. doi: 10.1016/j.phymed.2008.11.009. [PubMed: 19188054].

14. Kondo M, Hirano Y, Nishio M, Furuya Y, Nakamura H, Watanabe T. Xanthine oxidase inhibitory activity and hypouricemic effect of aspalathin from unfermented rooibos. J Food Sci. 2013;78(12):1935-9. doi: 10.1111/1750-3841.12304. [PubMed: 24261664]

15. Khan AU, Gilani AH. Selective bronchodilatory effect of Rooibos tea (Aspalathus linearis) and its flavonoid, chrysoeriol. Eur J Nutr. 2006;45(8):463-9. doi: 10.1007/s00394-006-0620-0. [PubMed: 17080260].

16. Bernfeld P. Alpha, and beta amylases. Methods Enzymol. 1955;1:149-51. doi: 10.1016/0076-6879(55)01021-5.

17. Najafian M, Ebrahim-Habibi A, Hezareh N, Yaghmaei P, Parivar K, Larijani B. Trans-chalcone: a novel small molecule inhibitor of mammalian alpha-amylase. Mol Biol Rep. 2011;38(3):1617-20. doi 10.1007/s11033-010-0271-3. [PubMed: 20857221].

18. Najafian M, Ebrahim-Habibi A, Yaghmaei P, Parivar K, Larijani B. Core structure of flavonoids precursor as an antihyperglycemic and antihyperlipidemic agent: an in vivo study in rats. Acta Biochim Pol. 2010;57(4):553-60. [PubMed: 21060897].

19. Najafian M, Amini S, Dehestani B, Parivar K, Ebrahim-Habibi A Thioflavin $\mathrm{T}$ effect in diabetic Wistar rats: reporting the antihyperglycemic property of an amyloid probing dye. Pharmacol Rep. 2015;67(2):364-9. doi: 10.1016/j.pharep.2014.10.013. [PubMed: 25712665].

20. Forouzanfar MH, Sepanlou SG, Shahraz S, Dicker D, Naghavi P, Pourmalek F, et al. Evaluating causes of death and morbidity in Iran, global burden of diseases, injuries, and risk factors study 2010. Arch Iran Med 2014;17(5):304-20. [PubMed: 24784860].

21. Skrha J. Diabetes mellitus-a global pandemic. Keynote lecture presented at the Wonca conference in Prague in June 2013. Eur J Gen Pract. 2014;20(1):65-8. doi: 10.3109/13814788.2013.847083. [PubMed: 24351018].

22. Whiting DR, Guariguata L, Weil C, Shaw J. IDF diabetes atlas: global estimates of the prevalence of diabetes for 2011 and 2030. Diabetes Res Clin Pract. 2011;94(3):311-21. doi: 10.1016/j.diabres.2011.10.029. [PubMed: 22079683].

23. Huseini HF, Kianbakht S, Hajiaghaee R, Dabaghian FH. Antihyperglycemic and anti-hypercholesterolemic effects of Aloe vera leaf gel in hyperlipidemic type 2 diabetic patients: a randomized double-blind placebo-controlled clinical trial. Planta Med. 2012;78(4):311-6. doi: 10.1055/s-0031-1280474. [PubMed: 22198821].

24. Machius M, Vertesy L, Huber R, Wiegand G. Carbohydrate and protein based inhibitors of porcine pancreatic alpha-amylase: structure analysis and comparison of their binding characteristics. J Mol Biol. 1996;260(3):409-21. doi: 10.1006/jmbi.1996.0410. [PubMed: 8757803].

25. de Beer D, Malherbe CJ, Beelders T, Willenburg EL, Brand DJ, Joubert E. Isolation of aspalathin and nothofagin from rooibos (Aspalathus linearis) using high-performance countercurrent chromatography: sample loading and compound stability considerations. J ChromatogrA. 2015;1381:29-36. doi: 10.1016/j.chroma.2014.12.078. [PubMed: 25614190].

26. Iswaldi I, Arraez-Roman D, Rodriguez-Medina I, Beltran-Debon R, Joven J, Segura-Carretero A, et al. Identification of phenolic compounds in aqueous and ethanolic rooibos extracts (Aspalathus linearis) by HPLC-ESI-MS (TOF/IT). Anal Bioanal Chem. 2011;400(10):364354. doi: 10.1007/s00216-011-4998-z. [PubMed: 21509483]. 
27. Dey B, Mitra A, Katakam P, Singla RK. Exploration of natural enzyme inhibitors with hypoglycemic potentials amongst Eucalyptus Spp. by in vitro assays. World J Diabetes. 2014;5(2):209-18. doi: 10.4239/wjd.v5.i2.209. [PubMed: 24748933].

28. DeFronzo RA. Pathogenesis of type 2 diabetes mellitus. Med Clin North Am. 2004;88(4):787-835. doi: 10.1016/j.mcna.2004.04.013. [PubMed 15308380].

29. El-Abhar HS, Schaalan MF. Phytotherapy in diabetes: Review on potential mechanistic perspectives. World J Diabetes. 2014;5(2):176-97. doi: 10.4239/wjd.v5.i2.176. [PubMed: 24748931].

30. Lopez-Candales A. Metabolic syndrome X: a comprehensive review of the pathophysiology and recommended therapy. J Med. 2001;32(56):283-300. [PubMed:11958275].

31. Alberton EH, Damazio RG, Cazarolli LH, Chiaradia LD, Leal PC, Nunes $\mathrm{R}$, et al. Influence of chalcone analogues on serum glucose levels in hyperglycemic rats. Chem Biol Interact. 2008;171(3):355-62. doi: 10.1016/j.cbi.2007.11.001. [PubMed: 18164698].

32. Son MJ, Minakawa M, Miura Y, Yagasaki K. Aspalathin improves hyperglycemia and glucose intolerance in obese diabetic ob/ob mice. Eur J Nutr. 2013;52(6):1607-19. doi: 10.1007/s00394-012-0466-6. [PubMed: 23238530].

33. Verges B. Lipid disorders in type 1 diabetes. Diabetes Metab. 2009;35(5):353-60. doi: 10.1016/j.diabet.2009.04.004. [PubMed: 19733492].

34. Gosavi A, Flaker G, Gardner D. Lipid management reduces cardiovascular complications in individuals with diabetes and prediabetes. Prev Cardiol. 2006;9(2):102-7. [PubMed:16603829].

35. Peluso MR. Flavonoids attenuate cardiovascular disease, inhibit phosphodiesterase, and modulate lipid homeostasis in adipose tissue and liver. Exp Biol Med (Maywood). 2006;231(8):1287-99. [PubMed 16946397].
36. Marnewick JL, Rautenbach F, Venter I, Neethling H, Blackhurst DM, Wolmarans P, et al. Effects of rooibos (Aspalathus linearis) on oxidative stress and biochemical parameters in adults at risk for cardiovascular disease. J Ethnopharmacol. 2011;133(1):46-52. doi: 10.1016/j.jep.2010.08.061. [PubMed: 20833235].

37. Kim M, Kim Y. Hypocholesterolemic effects of curcumin via upregulation of cholesterol 7a-hydroxylase in rats fed a high fat diet. Nutr Res Pract. 2010;4(3):191-5. doi: 10.4162/nrp.2010.4.3.191. [PubMed: 20607063].

38. Peschel D, Koerting R, Nass N. Curcumin induces changes in expression of genes involved in cholesterol homeostasis. J Nutr Biochem. 2007;18(2):113-9. doi: 10.1016/j.jnutbio.2006.03.007. [PubMed: 16713233].

39. Casaschi A, Maiyoh GK, Rubio BK, Li RW, Adeli K, Theriault AG. The chalcone xanthohumol inhibits triglyceride and apolipoprotein B secretion in HepG2 cells. J Nutr. 2004;134(6):1340-6. [PubMed: 15173394].

40. Ogawa $\mathrm{H}$, Ohno $\mathrm{M}, \mathrm{Baba} \mathrm{K}$. Hypotensive and lipid regulatory actions of 4-hydroxyderricin, a chalcone from Angelica keiskei, in strokeprone spontaneously hypertensive rats. Clin Exp Pharmacol Physiol. 2005;32(1-2):19-23. doi: 10.1111/j.1440-1681.2005.04147.x. [PubMed: 15730429].

41. Jang EM, Choi MS, Jung UJ, Kim MJ, Kim HJ, Jeon SM, et al. Beneficial effects of curcumin on hyperlipidemia and insulin resistance in high-fat-fed hamsters. Metabolism. 2008;57(11):1576-83. doi: 10.1016/j.metabol.2008.06.014. [PubMed:18940397].

42. Asai A, Miyazawa T. Dietary curcuminoids prevent high-fat dietinduced lipid accumulation in rat liver and epididymal adipose tissue. J Nutr. 2001;131(11):2932-5. [PubMed: 11694621].

43. Wang S, Chen B, Sun C. [Regulation effect of curcumin on blood lipids and antioxidation in hyperlipidemia rats]. Wei Sheng Yan Jiu. 2000;29(4):240-2. [PubMed: 12520931]. 